\title{
Duloxetine in the treatment of major depressive disorder
}

\author{
David J Goldstein \\ Department of Toxicology and \\ Pharmacology, Indiana University \\ School of Medicine, and PRN \\ Consulting, Indianapolis, IN, USA
}

Correspondence: David J Goldstein PRN Consulting, I 2 I 2 Kirkham Lane, Indianapolis, IN 46260, USA

Tel + $31757 \mid 0547$

Fax + | $31757 \mid 1029$

Email djgoldstein@consultprnc.com

\begin{abstract}
Since depression impacts all body systems, antidepressant treatments should relieve both the emotional and physical symptoms of depression. Duloxetine demonstrated antidepressant efficacy at a dose of $60 \mathrm{mg}$ qd in two placebo-controlled, randomized, double-blind studies and significantly improved remission rates compared with placebo. Duloxetine-treated patients had significant reduction in severity of the symptoms of depression as assessed by the HAM-D ${ }_{17}$, anxious symptoms as measured by the HAM-A and quality of life measures compared to placebo. Duloxetine also improved somatic symptoms, particularly painful symptoms which may have contributed to significantly improved remission rates compared to placebo. Approximately $10 \%$ of the 1139 patients with major depressive disorder in placebo-controlled trials discontinued treatment due to an adverse event, compared to $4 \%$ of the 777 patients receiving placebo. In addition to nausea (1.4\% incidence), which was the most common reason for discontinuation, dizziness, somnolence, and fatigue were the most common AEs reported as reasons for discontinuation and all were considered drug-related. Duloxetine treatment lacks effects on ECG, increases heart rate, and has little effect on blood pressure or weight.
\end{abstract}

Keywords: duloxetine, depression, antidepressant, SNRI, quality of life, pain.

\section{Introduction}

\section{Clinical presentation of major depressive disorder (MDD)}

Depression is associated with both significant functional impairment with work loss, impaired quality of life, and increased use of health care (Wells et al 1989; Hays et al 1995; Bosc 2000; Herrman et al 2002; Simon et al 2002;). Depression is a common, generally chronic, and debilitating psychiatric condition. It is increasingly recognized that depression affects the entire body including painful physical symptoms that may be part of a broader cluster of symptoms that constitute major depressive disorder (Detke et al 2002a, b), not merely emotional symptoms (mood and anxiety). Physical symptoms, including sleep disruption, fatigue, pain and discomfort, and appetite disturbance, are present in up to $80 \%$ of depressed patients (Gerber et al 1992). Physical symptoms occur in nearly all body systems and are often the presenting features in the non-psychiatric setting. Jackson et al (2001) found that five or more physical symptoms are a significant predictor of MDD in medical outpatients, with an odds ratio of 4.0. Furthermore, as evidence of their importance, physical symptoms, such as back pain and chest pain, predict greater severity of depression (Gerber et al 1992). Painful physical symptoms are highly prevalent among patients with depression (Simon and Von Korff 1991; Kroenke and Price 1993; Von Korff and Simon 1996; Gureje et al 1997; Gureje et al 1998; Simon et al 1999).

The DSM-IV (APA 1994) defines "major depressive episode" by a cluster of symptoms, including somatic symptoms, representing a change from previous functioning and which must be present for at least 2 weeks. This cluster includes either 1) depressed 
mood or 2) loss of interest or pleasure, and five of nine depressive symptoms - depressed mood; anhedonia; appetite or weight change; sleep difficulties; psychomotor agitation or retardation; fatigue or decreased energy; concentration difficulties; feelings of worthlessness or guilt; and recurrent thoughts of death or suicide. Increasing awareness of the association between depression and physical symptoms is reflected in the DSM-IV Text Revision (APA 2000), which describes associated features of major depressive episodes including "complaints of pain (eg, headaches or joint, abdominal, or other pains)."

The prospective naturalistic trial investigating response to SSRI therapy in primary care (the ARTIST study) (CoreyLisle et al 2004) indicated that most patients continue to have symptoms and impaired role functioning despite treatment (Klerman and Weissman 1992; Cronkite 1998; Corey-Lisle et al 2004). In that study, of the 601 patients randomized to treatment with 6 months of continuous therapy of therapeutic dose of paroxetine, fluoxetine, or sertraline, $46 \%$ failed to meet the response criteria of a 50\% reduction in their System Checklist (SCL-20) score. In addition, physical symptoms, especially painful symptoms, improved less than emotional symptoms. Unfortunately, in clinical practice, many patients receive inadequate dose strength or treatment duration (Keller et al 1986; Hirschfeld et al 1997), further reducing the effectiveness of treatment. Patients who achieve only partial response to treatment of a depressive episode (partial recovery) are more likely to have subsequent episodes.

Many patients who fully recover from a depressive episode eventually relapse, and each subsequent relapse may heighten the risk of a chronic, non-remitting course (Belsher and Costello 1988). The number of prior episodes predicts the likelihood of having subsequent episodes. It has been found that at least $60 \%$ of patients have a second episode after their initial episode; after two episodes patients have a $70 \%$ chance of having a third episode; and after three episodes, patients have a $90 \%$ chance of having a fourth episode (Cohen et al 2004). In a 16-year follow-up of depressed inpatients, 50\% showed either a chronic course or a series of relapses leading to a chronic course. As a consequence, the recommended duration of treatment and maintenance has been extended proportionately with the number and chronicity of prior depressive episodes (Kupfer et al 1992).

Other aspects associated with poorer outcome and/or disease persistence include dysthymic disorder, marked severity of the initial episode, and the presence of some chronic general medical conditions (eg, diabetes) (Swindle et al 1998), physical symptoms, and pain. In a study of patients given selective serotonin reuptake inhibitor (SSRI) therapy, physical symptoms were less likely to improve than emotional symptoms, well-being, and work/social function (Greco et al 2004). Increased prevalence rates of depression are found among patients with neurologic (23\%) and cardiovascular disease $(20 \%-27 \%)$, cancer $(25 \%-42 \%)$, diabetes (8.5\%-27.3\%), and HIV (5.6\%-12.2\%) (Sutor et al 1998). The presence of major diagnosed medical conditions is a risk factor for a chronic course of depression over 4 years from the initiation of treatment (Swindle et al 1998).

Simon et al (1999) performed an analysis of 1146 subjects with major depression from a WHO screening survey of 25,916 primary care patients in 14 countries. Approximately $50 \%$ of those with major depression also reported at least three unexplained physical symptoms. In addition, the number of unexplained physical symptoms was more than three times higher in those with major depression $(4.4 \pm 4.2)$ than in those without major depression (1.2 \pm 1.9$)$.

\section{Etiology of MDD}

Because depression impacts all body systems (Kroenke and Price 1993; Posse and Hallstrom 1998), it is no surprise that investigations attempting to determine the effects of depression on hormones, neurotransmission, brain imaging, sleep architecture, immune function, and so on, have tended to identify differences between depressed patients and normal subjects. However, many of these investigations have not been replicated, or show significant overlap between depressed and non-depressed groups leading to subsequent investigations of subgroups. Such investigations are further complicated by the temporal adaptation that occurs in many biological systems, resulting in differing effects after acute and chronic stress (Goldstein and Potter 2004).

Numerous biochemical mediators have been identified as potential factors related to the development of depression (Goldstein and Potter 2004). Among the best characterized neurotransmitters involved in depression are serotonin (5-HT) and norepinephrine (NE) (Tran et al 2003). Enhancing both 5-HT and NE neurotransmission simultaneously may provide greater efficacy and faster onset of action than enhancing either mechanism alone (Danish University Antidepressant Group 1986, 1990; Nelson et al 1991; Tran et al 2003). Descending 5-HT and NE pathways normally help to suppress pain inputs even when they cause minor discomfort. However, when these neurotransmitter systems malfunction, deficient inhibition from the descending pathways may allow routine sensory input to be interpreted as 
painful physical symptoms. Increasing neurotransmission of both 5-HT and NE may offer greater antidepressant efficacy when compared with potentiation of a single neurotransmitter (Nelson 1998), and may be of clinical utility in the alleviation of painful physical symptoms associated with depression.

\section{Epidemiology and relevant risk factors of MDD}

Lifetime prevalence estimates for depression vary across studies, perhaps as a result of differences among instruments and survey methods used to identify the disorder. It is estimated that the lifetime risk for MDD ranges from 10\% to $25 \%$ for women and from $5 \%$ to $12 \%$ for men.

The National Comorbidity Survey Replication (NCS-R), conducted with a nationally representative United States sample between 2001 and 2002, supported earlier findings from its predecessor, the National Comorbidity Study (Kessler et al 1994, 1996, 1997). It confirmed that MDD is the single most prevalent psychiatric disorder (Kessler et al 2003). Lifetime prevalence was $16.2 \%$, with $6.6 \%$ of the population experiencing an episode in a 12-month period. Lifetime prevalence was greater among women than men and greater among Caucasians than non-Hispanic African-Americans. In addition, lifetime depression was more common among homemakers (12 month only), the previously married (lifetime only), those with less than 12 years of education, and those living in or near poverty. Age of onset tended to rise rapidly from the late teens, with the suggestion that onset rates were earlier for more recent birth cohorts.

Lifetime MDD was comorbid with another psychiatric disorder in nearly $75 \%$ of respondents. The most common lifetime comorbid conditions were: anxiety (59\%), impulse control disorder (30\%), and substance use disorder (24\%). MDD was associated with role impairment for nearly all respondents (96.9\%) with 12-month MDD. Impairment tended to be most severe in the social role domain $(43.4 \%$ severe or very severe) and least in the work role domain $(28.1 \%$ severe or very severe). Despite work being the least impaired domain, respondents with 12-month MDD reported a mean of 35.2 days in the past year in which they were totally unable to work or perform usual activities. Regardless of prevalence estimates, most researchers agree that major depression is under-diagnosed and under-treated (Hirschfeld et al 1997).

\section{Approaches to MDD treatment}

According to published practice guidelines, the three primary treatment modalities for major depression are pharmacotherapy, psychotherapy, and their combination (Schulberg et al 1999; APA 2000). Selection of an initial treatment for acute depression is based on several factors including severity of symptoms, physiological and psychiatric comorbidities, subtype of depression, and patient preference. Both pharmacotherapy and psychotherapy are also recommended for continuation treatment (ie, 16-20 weeks following remission) and maintenance treatment to prevent further recurrences of depressive episodes (APA 2000). A recent meta-analysis of randomized, controlled, double-blind clinical trials for MDD found that antidepressants and psychotherapy were both more effective than control conditions (Casacalenda et al 2002). The literature is inconsistent about whether pharmacotherapy and psychotherapy in combination are superior to either treatment modality alone (see Table 1).

Numerous clinical trials have assessed the efficacy of antidepressants, generally indicating that antidepressant treatment of major depression is superior to placebo treatment (Dunbar et al 1993; Ellingrod and Perry 1995; Ballenger 1996; Croft et al 1999; Feighner and Overo 1999; Gorman 1999). The majority of studies that compare multiple antidepressants including SSRIs and tricyclic antidepressants (TCAs) show no significant efficacy differences between them (Holliday and Plosker 1993; Bennie et al 1995; Patris et al 1996; Sechter et al 1999; Stahl 2000; Kroenke et al 2001), but with very high sample size or with meta-analysis using data from multiple studies, TCAs and dual reuptake inhibitors show greater efficacy than SSRIs (Thase 2002). The core difference between the TCAs and SSRIs lies in safety profiles and tolerability. SSRIs lack the potentially serious side-effects of TCAs such as orthostatic hypotension, anticholinergic effects, and cardiac arrhythmia (Peretti et al 2000). SSRIs are also non-toxic in overdose (Mason et al 2000; Peretti et al 2000), their titration tends to be much simpler, and patient dropout rates are lower (Mulrow et al 2000). Dual reuptake inhibitors, such as duloxetine, can maintain the safety and tolerability advantages of the SSRIs.

In the past, clinicians strived for patients to "feel better" (achieve antidepressant "response"); however, the goal has shifted to getting patients "well" or "virtually symptom free" ("remission") because patients who experience only partial response to treatment of a depressive episode have a greater likelihood of developing subsequent episodes and of continuing to experience only partial recovery between episodes. Remission is ordinarily measured in clinical trials by achievement of a Hamilton Depression Rating Scale (HAM-D) score of $\leq 7$ (Keller 2003). 
Table I Treatments for major depressive disorder

\begin{tabular}{lll}
\hline & & Examples \\
\hline Psychotherapy & Cognitive-Behavioral (CBT) & \\
Interpersonal psychotherapy (IPT) & Fluoxetine, paroxetine, sertraline \\
& SSRIs & Amitriptylline, nortriptyline, trazodone, \\
& Tricyclics & Venlafaxine \\
& SNRI & Bupropion \\
& DNRI & St. John's wort (Gaster and Holroyd 2000; \\
& Non-traditional & Williams et al 2000) \\
Other therapies & Exercise (Penninx et al 2002) & \\
& Electro-convulsive therapy (ECT) (Weiner and Coffey 1993) & \\
& Acupuncture & \\
& Vagus nerve stimulation (VNS) - electrical stimulation of the left & \\
& vagus nerve in the neck via anterior chest wall- implanted & \\
& stimulator & \\
& Psychosurgery - surgical intervention to sever nerve fibers & \\
& in the brain & \\
& Transcranial magnetic stimulation (r-TMS) - stimulation of local \\
& electrical currents in the brain via a strong magnetic field \\
& created by a stimulating coil
\end{tabular}

Abbreviations: DNRI, dopamine-norepinephrine reuptake inhibitor; SNRI, serotonin-norepinephrine reuptake inhibitor; SSRI, selective serotonin reuptake inhibitor.

\section{Duloxetine}

Duloxetine, (+)-(S)- $N$-methyl- $\gamma-(1-$ naphthyloxy)-2-thiophenepropylamine hydrochloride, is a potent inhibitor of both 5-HT and NE reuptake, possesses comparable affinities in binding to NE and 5-HT transport sites, and has no significant affinity for cholinergic, histaminergic, dopaminergic, opioid, glutamate, GABA, cholinergic and adrenergic receptors in vitro (Bymaster et al 2001) and does not inhibit monoamine oxidase. Duloxetine undergoes extensive metabolism, but the major circulating metabolites have not been shown to contribute significantly to its pharmacologic activity. Preclinical studies have shown that duloxetine is a potent inhibitor of neuronal 5-HT and NE reuptake and a less potent inhibitor of dopamine reuptake.

Although the exact mechanisms of the antidepressant and central pain inhibitory action of duloxetine in humans are unknown, the antidepressant and pain inhibitory actions are believed to be related to its potentiation of 5-HT and NE activity in the central nervous system (CNS) (see Pharmacokinetics).

\section{Pharmacokinetics and metabolism}

Early duloxetine development was performed using a different formulation and lower dosage (Berk et al 1997). After failing to differentiate from placebo in depression Phase II/III trials, duloxetine was further evaluated and the present formulation and higher dosages were studied, beginning with new Phase I studies (Table 2). The absorption, distribution, metabolism, and elimination of duloxetine are presented in Table 3 (Lantz et al 2003; Skinner et al 2003, 2004; Eli Lilly and Co 2004; Suri et al 2005; Thase et al 2005; Anonymous 2006).

\section{Efficacy}

\section{Duloxetine trials}

The efficacy of duloxetine for the acute treatment of major depressive disorder (MDD) was established in eight double-blind, randomized, placebo-controlled studies in adult outpatients who met DSM-IV (APA 1994) criteria for major depression (see Table 3 for study details). In the placebo-controlled MDD efficacy trials duloxetine was consistently significantly more effective than placebo at doses $\geq 60 \mathrm{mg} /$ day.

Studies 1 and 2 were designed to test proof of concept in two underpowered trials in which one trial (Goldstein et al 2002) showed superiority of duloxetine over placebo. Both of these studies used markedly under-powered fluoxetine comparator treatment arms.

Studies 3 and 4 investigated a low and intermediate dose of duloxetine. In Study 3 paroxetine treatment was superior to placebo treatment, but duloxetine was not. In Study 4 (Goldstein et al 2004b), duloxetine treatment at both dosages was superior to placebo treatment, whereas paroxetine was not. Although the duloxetine vs paroxetine comparison was not intended in these trials, Study 4 showed duloxetine at $40 \mathrm{mg}$ bid was superior to paroxetine $20 \mathrm{mg}$ which performed poorly in this trial. If these trials 


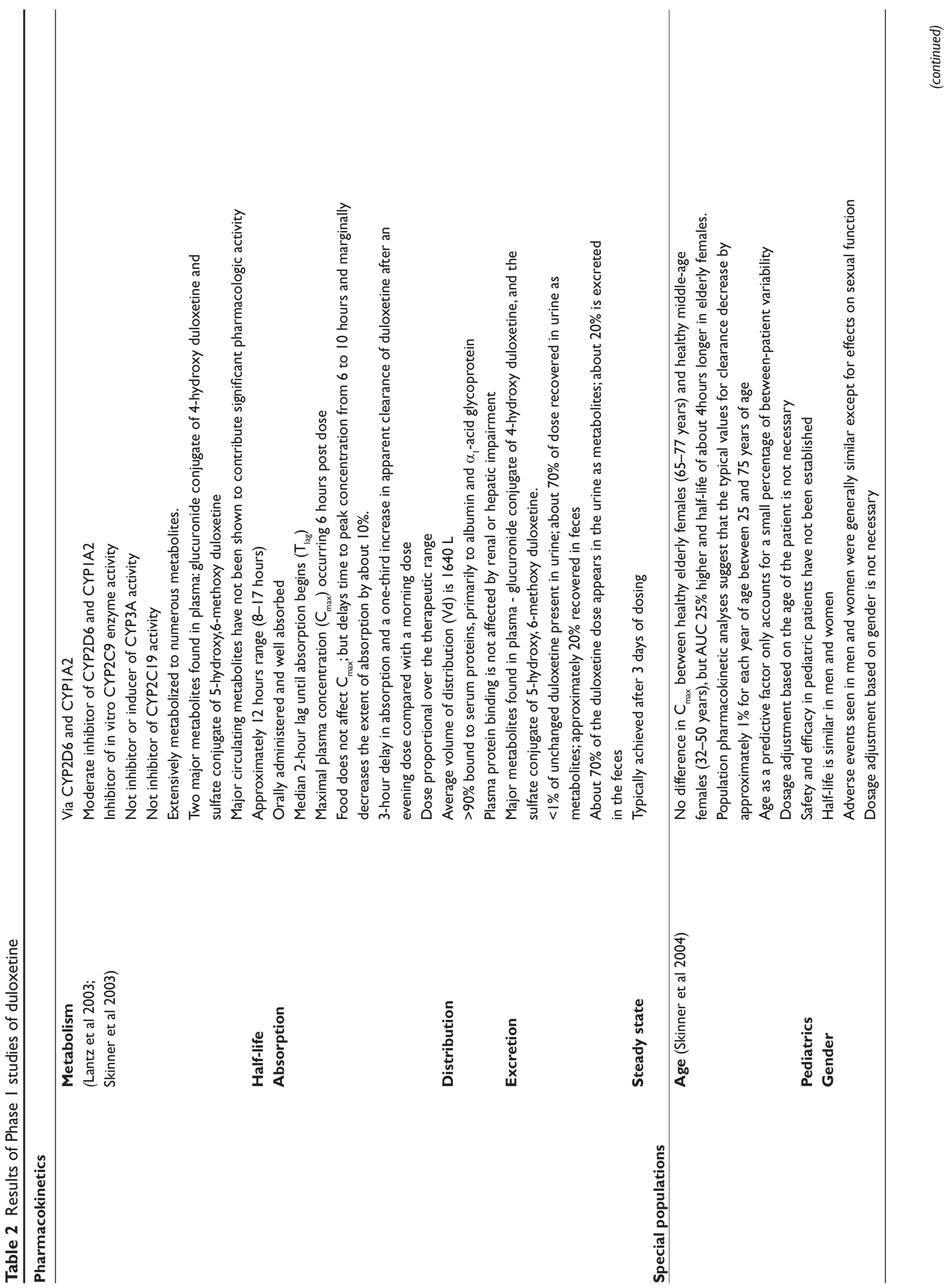




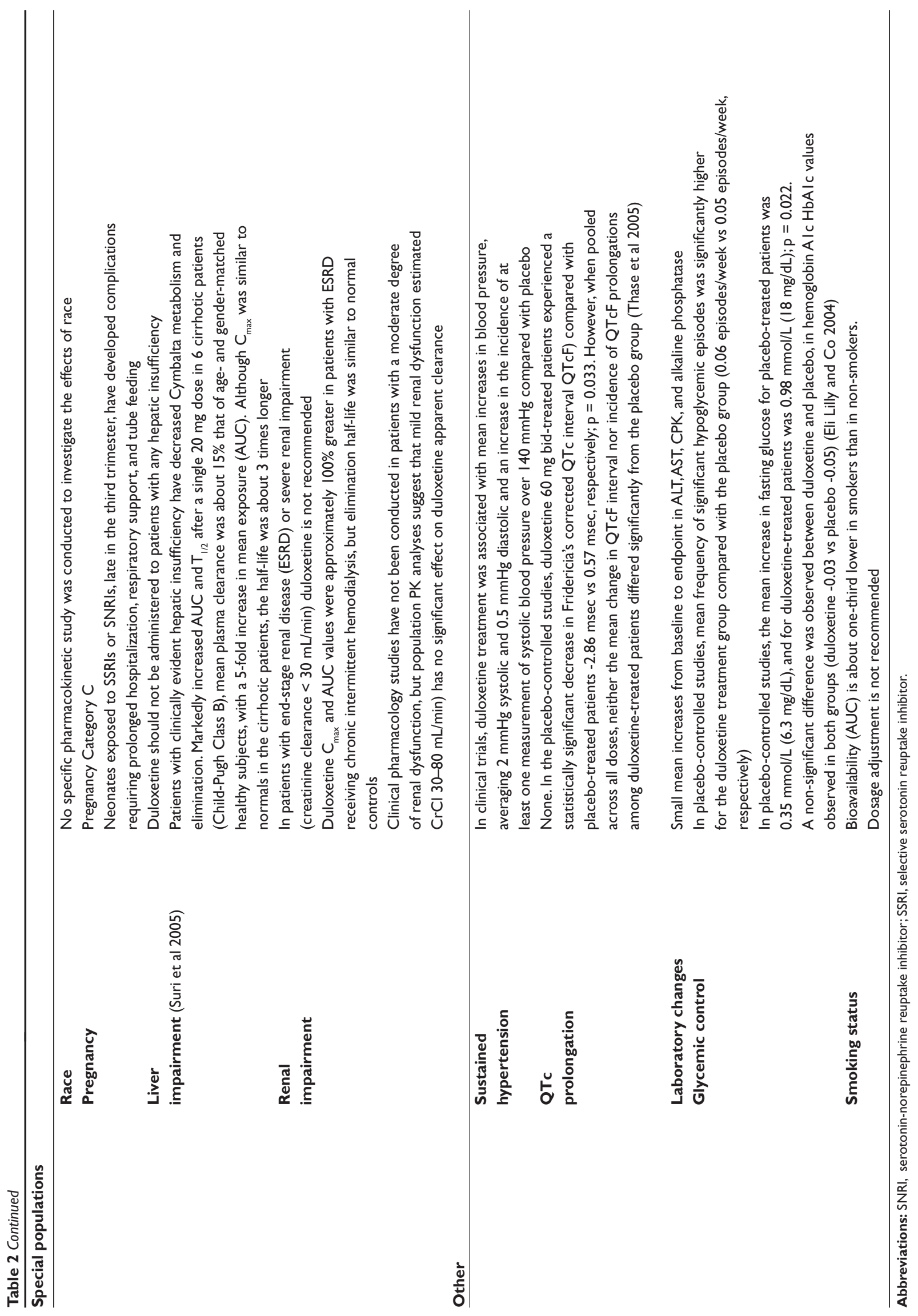




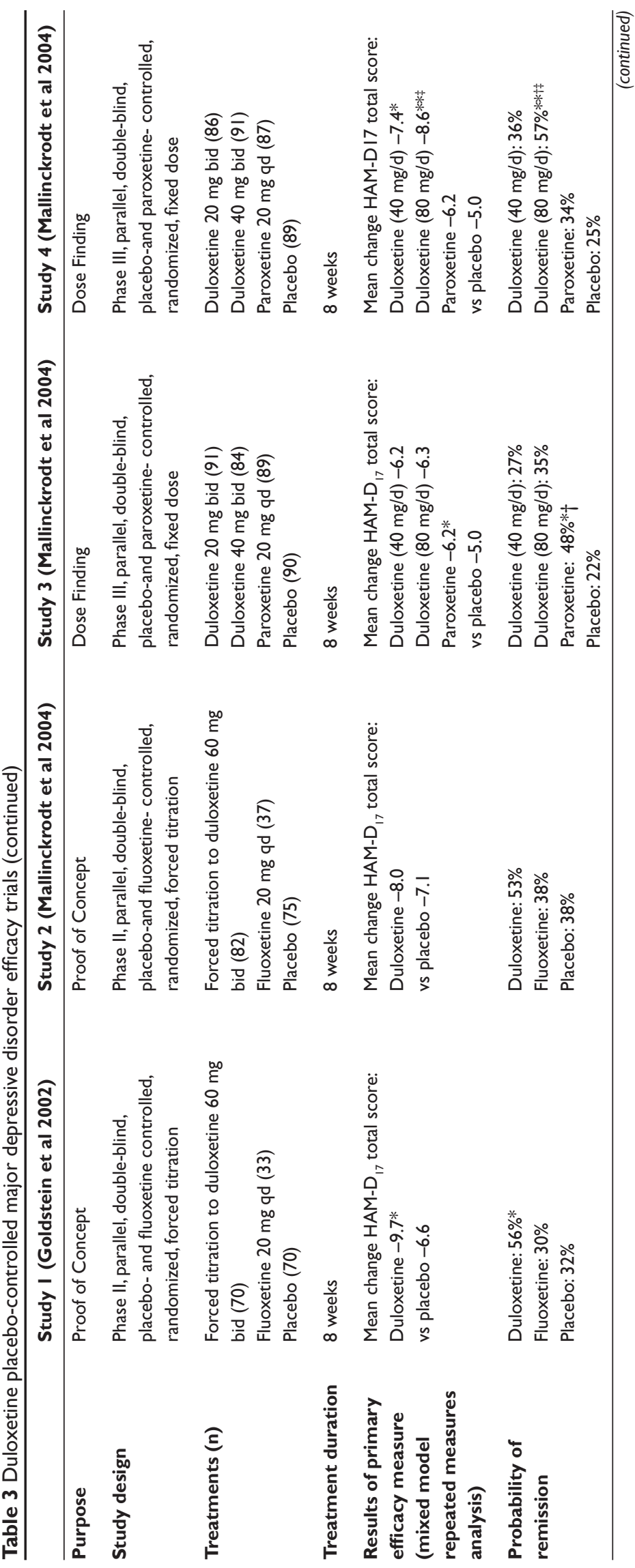




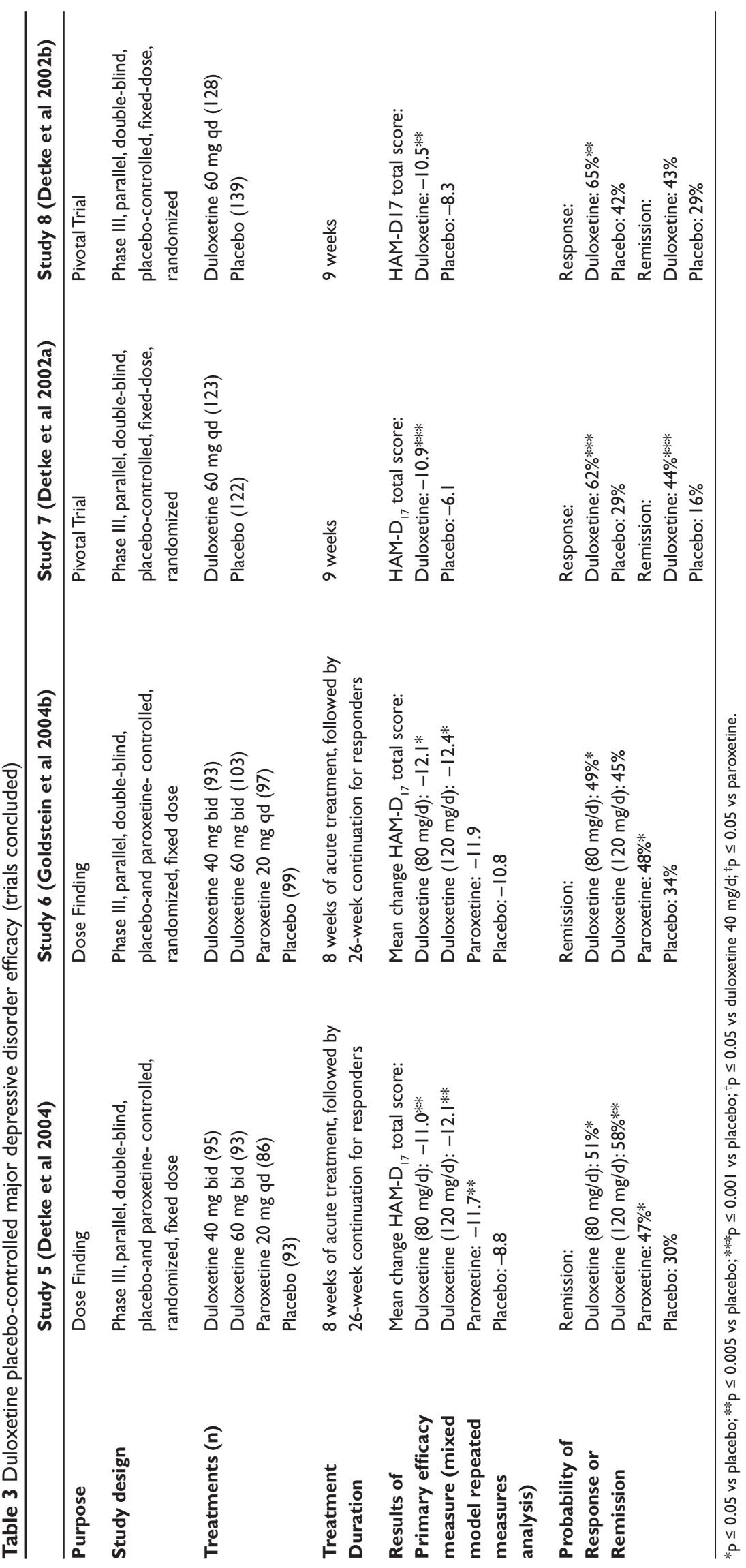


were pooled, the results would likely show that duloxetine $40 \mathrm{mg}$ bid was superior to placebo at the higher dose and that paroxetine was not. Duloxetine would have been numerically superior, but not statistically significantly different from paroxetine. Studies 5 and 6 investigated an intermediate dose and high dose of duloxetine. The intermediate dose of $40 \mathrm{mg}$ bid was the same as that used in Studies 3 and 4 so that there would be a common reference dose for inferring the relationship of the low dose in Studies 3 and 4 to the high dose in Studies 5 and 6. Study 5 showed that both duloxetine doses and the paroxetine dose were superior to placebo, but duloxetine and paroxetine treatments did not differ statistically. Study 6 showed that both doses of duloxetine were superior to placebo, but paroxetine was not. If these studies had been pooled, both doses of duloxetine would have been significantly superior to placebo, but paroxetine treatment would not. Duloxetine would have been numerically superior, but not statistically significantly different from paroxetine.

Studies 7 and 8 (Detke et al 2002a, b) were intended to evaluate whether a single $60 \mathrm{mg}$ dose of duloxetine daily would be sufficient for treatment. Both studies confirmed the efficacy of $60 \mathrm{mg}$ qd. It is valuable to note that the sample sizes were higher in these studies, compared with the prior studies, so that a smaller effect could be identified, possibly accounting for the highly significant differences from placebo treatment.

\section{Other duloxetine MDD trials}

Additional trials (Table 4) were performed to meet regulatory requirements or expand an understanding of the usefulness of duloxetine.

Study 9 was an open label safety trial used to increase the number of patients treated for 1-year in the regulatory package. The long-term efficacy of duloxetine in elderly patients was demonstrated in the subset of patients aged 65 years and older $(\mathrm{n}=101)$ who participated in this study (Eli Lilly and Co 2004). A comparison of visit-wise mean changes in the CGI-S score between elderly patients (age $\geq 65, \mathrm{n}=101$ ) and those patients in the study aged $<65(\mathrm{n}=1178)$ revealed a somewhat more rapid onset of efficacy in younger patients; however, at subsequent visits, the differences between age groups became progressively smaller, and mean changes were essentially equal at endpoint (Eli Lilly and Co 2004).

Study 10 (see Table 4) was a relapse-prevention study in which all patients received open-label duloxetine (60 mg qd) during an initial 12-week acute phase. Acute-phase treatment responders were randomized to treatment with either placebo or duloxetine $60 \mathrm{mg}$ qd for 26 weeks (continuation phase). Duloxetine treatment significantly delayed relapse.

Study 11 (Table 4) was a switching study. Patients exhibiting suboptimal response or poor tolerability to their current antidepressant medication, ie, citalopram ( $\leq 40 \mathrm{mg} / \mathrm{d})$, escitalopram ( $\leq 20 \mathrm{mg} / \mathrm{d})$, fluvoxamine $(\leq 150 \mathrm{mg} / \mathrm{d})$, paroxetine ( $\leq 40 \mathrm{mg} / \mathrm{d})$, sertraline ( $\leq 150 \mathrm{mg} / \mathrm{d})$, or venlafaxine $(\leq 150$ $\mathrm{mg} / \mathrm{d}$ ) switched directly to duloxetine (60 mg qd) without intermediate tapering or titration ("switching group"). The other half of the patients initiated treatment with duloxetine at either $30 \mathrm{mg}$ qd or $60 \mathrm{mg}$ qd. Duloxetine therapy at $60 \mathrm{mg}$ qd showed significantly greater improvement after 1 week of therapy when compared with those initiating therapy at 30 mg QD. After switching, duloxetine could be titrated up to $120 \mathrm{mg}$ qd. At the end of the study (12 weeks), the efficacy was similar for all groups. Using an SSRI or venlafaxine for at least 1 week reduced the number of advese events experienced by patients who switched to duloxetine compared with the adverse event profile experienced by patients who began therapy with duloxetine.

\section{Pooled MDD efficacy results and subset analyses MDD efficacy in males and females}

Data pooled from 7 acute trials preformed in the US showed that duloxetine was more effective than placebo in both males and females for change in $\mathrm{HAMD}_{17}$, remission, response, and quality of life (Kornstein et al 2006). There was no statistically significant interaction by gender, indicationg that duloxetine efficacy is similar for both males and females.

\section{MDD efficacy in Hispanic and African-American patients}

The efficacy of duloxetine did not differ between subsets of African-American and Caucasian patients who participated in seven double-blind, placebo-controlled studies (Bailey et al 2006). The efficacy of duloxetine in the African-American patients (as assessed using HAM-D ${ }_{17}$, CGI-S, and PGI-I scales) did not differ significantly from the efficacy observed in the Caucasian patients who participated in the seven studies.

\section{Efficacy in the treatment of anxious symptoms of depression}

Most patients with MDD have anxious symptoms associated with their depression. Effective relief of anxious symptoms is an important factor in the successful treatment of depression.

Dunner et al (2003) reported the efficacy of duloxetine in treating depression-associated anxious symptoms in Studies 


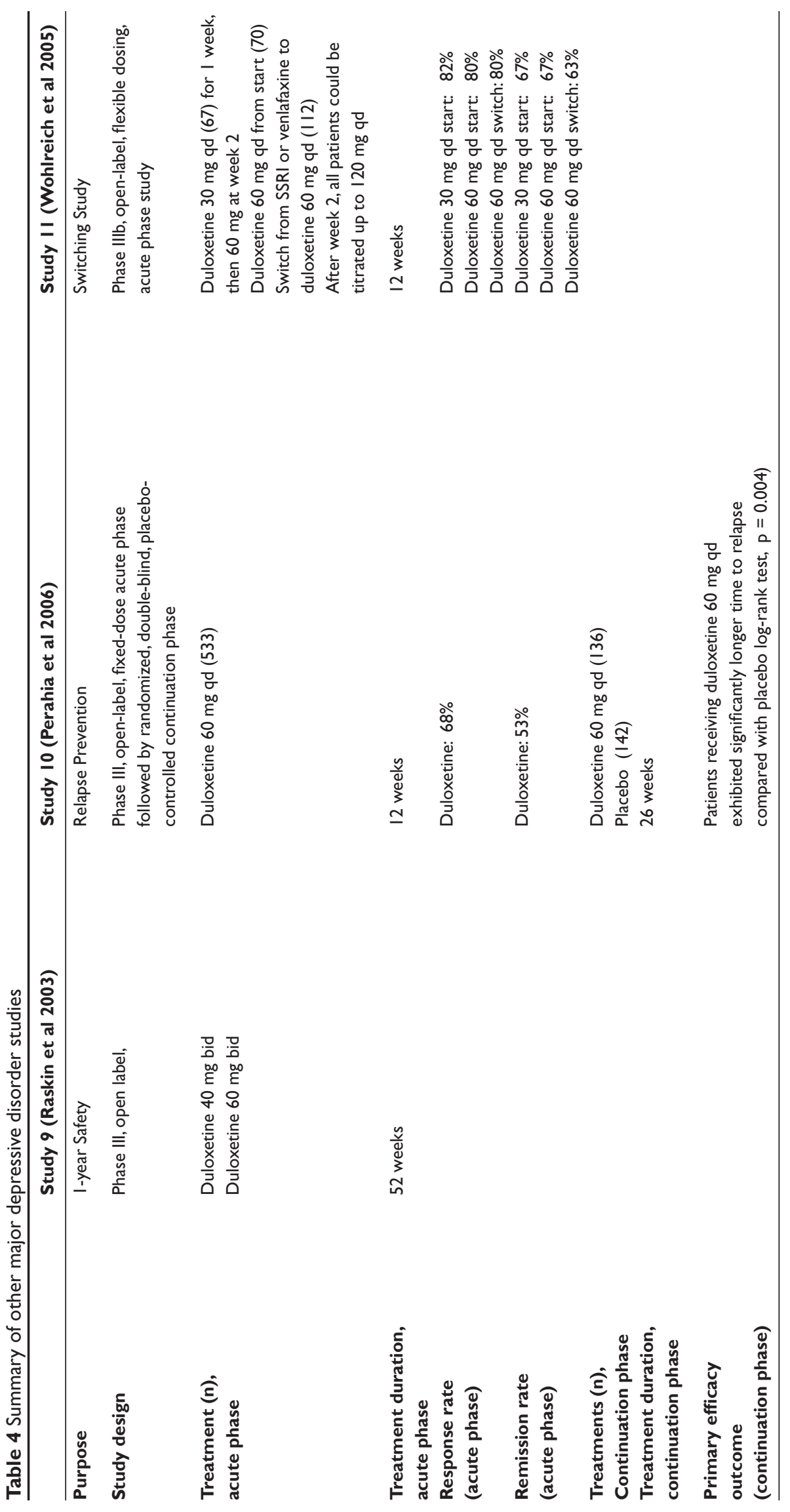


1, 4, 7, and 8 using the HAM-D ${ }_{17}$ anxiety/somatization subscale, HAM-D ${ }_{17}$ Item 10 (anxiety-psychological) and the Hamilton Anxiety Rating Scale (HAMA). Duloxetine was significantly more effective than placebo at relieving anxious symptoms.

In addition, in Study 5, duloxetine (80 mg/day or 120 $\mathrm{mg} /$ day) significantly improved both the HAM-D ${ }_{17}$ anxiety/ somatization subscale and HAMA scale more than placebo (Detke et al 2004).

\section{Efficacy in patients with melancholic features} A pooled efficacy analysis of data from Studies 1-8, demonstrated that the advantage of duloxetine over placebo treatment did not differ significantly between melancholic $(n=1278)$ and non-melancholic patients $(n=635)$ (Mallinckrodt et al 2005). Furthermore, duloxetine was significantly superior to placebo in both melancholic and non-melancholic cohorts $(\mathrm{p} \leq 0.001)$ for mean change in HAM-D ${ }_{17}$ total score, CGI-S, and PGI-I scales.

Efficacy in the treatment of painful physical symptoms associated with depression

Visual analogue scales assessing the severity of overall pain, headache, back pain, and shoulder pain, and interference with daily activities, and amount of time while awake were assessed in many of the clinical trials. Studies 4, 7, and 8 each showed that some painful symptoms improved with duloxetine at $60 \mathrm{mg}$ or $80 \mathrm{mg} / \mathrm{d}$ (Goldstein et al 2004a). In Studies 7 and 8, duloxetine consistently reduced bodily pain severity, as measured by visual analog scales (VAS) assessing severity of overall pain, severity of headaches, severity of back pain, severity of shoulder pain, interference with daily activities, and amount of time in pain while awake (Detke et al 2002a, b). Results from the analysis of pooled data (Brannan et al 2005; Fava et al 2004) showed that duloxetine reduced pain severity by $22 \%-41 \%$ (depending on the item) compared with 5\%-18\% reduction for placebo treatment.

\section{Safety and tolerability}

Duloxetine was evaluated in 2418 patients with MDD representing 1099 patient-years of exposure including 993 patients treated for at least 180 days and 445 exposed for at least 1 year. Among these 2418 patients, 1139 were enrolled in Studies 1-8 and 1279 patients were enrolled in Studies 9-11. Safety was assessed by adverse events, physical examinations, vital signs, weight, laboratory analyses, and ECGs.

\section{Tolerability profile in MDD}

In the placebo-controlled database, the incidence of serious adverse events for duloxetine-treated patients $(0.3 \%, 3 / 1139)$ was one-half the rate of placebo-treated patients $(0.6 \%, 5 / 777)$. In the placebo-controlled database, the incidence of adverse events reported as the reason for discontinuation was significantly greater for patients receiving duloxetine compared with placebo (9.7\% vs 4.2\%, respectively; $\mathrm{p}<0.001$ (Tran et al 2003). Nausea was the most common adverse event resulting in discontinuation of duloxetine therapy $(1.4 \%$ vs $0.1 \%$ respectively (Greist et al 2004). The median time to onset of nausea among duloxetine-treated patients was 1 day, while the median duration was 7 days (Greist et al 2004). After the first week of therapy, the incidence of new cases of nausea was essentially equal to placebo. Other adverse events resulting in discontinuation in $\geq 0.5 \%$ of duloxetine-treated patients were somnolence, dizziness, fatigue, and insomnia. In Study 9, the rate of discontinuation due to adverse events was $17.0 \%$ in the 1-year trial at 80-120 mg/day (Raskin et al 2003).

\section{Adverse event profile}

The stated frequencies of adverse events (AEs) represent the proportion of individuals who experienced, at least once, a treatment-emergent adverse event of the type listed. An event was considered treatment-emergent if it first occurred or worsened after receiving study drug therapy without respect to causation.

\section{Treatment-emergent adverse events}

The incidences of treatment-emergent AEs that occurred in at least $2 \%$ of patients treated with Duloxetine, and at a rate greater than placebo, are listed in Table 5 (Eli Lilly and Co 2004). These AEs occurred in patients with MDD treated with duloxetine in a dose range of $40-120 \mathrm{mg} / \mathrm{d}$. The most commonly observed adverse events in duloxetine-treated MDD patients (incidence of 5\% or greater and at least twice the incidence in placebo patients) were nausea, dry mouth, constipation, decreased appetite, fatigue, somnolence, and increased sweating.

Headache was commonly reported, but was more frequently reported by placebo-treated patients (16.9\%) than by duloxetine-treated patients $(15.0 \%)$. Of the patients that reported nausea with duloxetine, most (94\%) reported it as mild or moderate in intensity (Greist et al 2004). 
Table 5 Treatment-emergent adverse events with frequency of at least $2 \%$ for duloxetine treatment and greater frequency for duloxetine than placebo in placebo-controlled trials of major depressive disorder (Eli Lilly and Co 2004)

\begin{tabular}{|c|c|c|c|}
\hline & $\begin{array}{l}\text { Placebo }(\mathbf{N}=777) \\
\text { n (\%) }\end{array}$ & $\begin{array}{l}\text { Duloxetine (N = I I39) } \\
\text { n (\%) }\end{array}$ & P value \\
\hline Nausea & $54(6.9)$ & 227 (19.9) & $<0.001$ \\
\hline Dry mouth & $49(6.3)$ & $166(14.6)$ & $<0.001$ \\
\hline Constipation & $31(4.0)$ & I 30 (I I.4) & $<0.001$ \\
\hline Insomnia & $47(6.0)$ & $113(9.9)$ & 0.002 \\
\hline Dizziness & $37(4.8)$ & I0I (8.9) & $<0.001$ \\
\hline Fatigue & $29(3.7)$ & $94(8.3)$ & $<0.001$ \\
\hline Diarrhea & $435(.5)$ & $88(7.7)$ & 0.065 \\
\hline Somnolence & $21(2.7)$ & 81 (7.I) & $<0.001$ \\
\hline Sweating increased & $12(1.5)$ & $70(6.1)$ & $<0.001$ \\
\hline Appetite decreased & $15(1.9)$ & $67(5.9)$ & $<0.001$ \\
\hline Vomiting & $20(2.6)$ & $52(4.6)$ & 0.027 \\
\hline Vision blurred & $10(1.3)$ & $4 \mid(3.6)$ & 0.002 \\
\hline Tremor & $6(0.8)$ & $31(2.7)$ & 0.002 \\
\hline Libido decreased & $4(0.5)$ & $29(2.5)$ & $<0.001$ \\
\hline Weight decreased & $4(0.5)$ & $27(2.4)$ & 0.001 \\
\hline Anorgasmia & $0(0.0)$ & $252.2)$ & $<0.001$ \\
\hline Hot flashes & $6(0.8)$ & $242.1)$ & 0.024 \\
\hline Erectile dysfunction ${ }^{\mathrm{a}}$ & $2(0.8)$ & $16(4.2)$ & 0.013 \\
\hline Ejaculation delayed ${ }^{\mathrm{a}}$ & $2(0.8)$ & $10(2.6)$ & 0.139 \\
\hline Ejaculation disorder ${ }^{\mathrm{a}}$ & I $(0.4)$ & $8(2.1)$ & 0.093 \\
\hline
\end{tabular}

adjusted for gender.

Abbreviations: $\mathrm{N}$, number of patients in the group; $\mathrm{n}$, number of patients who reported the event.

\section{Discontinuation-emergent events}

Following abrupt discontinuation, in MDD placebo-controlled clinical trials of up to 9 weeks' duration, the following symptoms occurred at a rate greater than or equal to $2 \%$ and at a significantly higher rate in duloxetine-treated patients compared to those discontinuing from placebo: dizziness, nausea, headache, paresthesia, vomiting, irritability, and nightmare (Eli Lilly and Co 2004). A gradual reduction in dose rather than abrupt cessation is recommended.

\section{Effects on male and female sexual function}

Because changes in sexual desire, performance, and satisfaction are manifestations of MDD, but can occur with use of many antidepressants, these were evaluated by both adverse events and the Arizona Sexual Experience Scale (ASEX) (McGahuey et al 2000) in Studies 3, 4, 5, and 6 (Delgado et al 2005). Based on adverse events, duloxetine-treated males had more frequent complaints of abnormal orgasm, ejaculatory dysfunction, decreased libido, erectile dysfunction, and delayed ejaculation and duloxetine-treated females reported more abnormal orgasm and decreased libido. Based on the ASEX, duloxetine-treated males had more difficulty reaching orgasm (ASEX Item 4). Duloxetine-treated females did not experience more sexual dysfunction on duloxetine than on placebo. Paroxetine-treated patients had statistically significantly more sexual dysfunction than duloxetine-treated patients $(\mathrm{p}=0.015)$.

\section{Elderly}

Clinical studies of duloxetine did not suggest a difference in adverse event rates in people over or under 65 years of age (Eli Lilly and Co 2004).

\section{Changes in vital signs and ECGs \\ Cardiovascular effects}

Blood pressure and heart rate: Duloxetine treatment, for up to 9 weeks in MDD placebo-controlled clinical trials of $40-120 \mathrm{mg} / \mathrm{d}$ doses, caused mean increases in blood pressure, averaging $2 \mathrm{mmHg}$ systolic and $0.5 \mathrm{mmHg}$ diastolic and an increase in the incidence of at least one measurement of systolic blood pressure over $140 \mathrm{mmHg}$ compared with placebo. 
Blood pressure should be measured prior to initiating treatment and periodically measured throughout treatment (Thase et al 2005).

In the placebo-controlled database, the mean change in heart rate for duloxetine-treated patients was 1.4 beats per minute, while mean changes in systolic and diastolic blood pressure were $0.8 \mathrm{mmHg}$ and $0.9 \mathrm{mmHg}$, respectively (Thase et al 2005). At the highest duloxetine dose of $120 \mathrm{mg} / \mathrm{d}$, mean increases in systolic and diastolic blood pressure were less than $2 \mathrm{mmHg}$.

In the placebo-controlled database, there was no significant difference in the incidence of sustained elevation in blood pressure (sustained increases of either systolic or diastolic pressures) between patients receiving duloxetine $(1.3 \%$, $14 / 1116)$ or placebo $(0.8 \%, 6 / 757)$ (Thase et al 2005).

Electrocardiogram changes: Electrocardiograms were obtained from 321 duloxetine-treated patients with major depressive disorder and 169 placebo-treated patients in clinical trials lasting up to 8 weeks. In the placebo-controlled database, mean changes in corrected QT intervals did not differ significantly between duloxetine- and placebo-treated patients (Thase et al 2005). Duloxetine-treated patients actually had small decreases in most assessments, including those patients receiving doses of $120 \mathrm{mg} / \mathrm{d}$. In addition, the incidence of abnormal ECGs (centrally read and/or investigator rated), and the incidence of corrected QT intervals increased $>30 \mathrm{msec}$ were essentially identical for duloxetine- and placebo-treated patients. Thus, duloxetine therapy has not been associated with QTc prolongation.

Duloxetine was not associated with the development of clinically significant ECG abnormalities. No clinically significant differences were observed for QT, PR, and QRS intervals between duloxetine-treated and placebo-treated patients.

\section{Weight changes}

Many antidepressants are associated with weight gain that can lead to dissatisfaction with treatment and premature discontinuation of therapy. In MDD placebo-controlled clinical trials, patients treated with duloxetine for up to 9 weeks experienced a mean weight loss of approximately $0.5 \mathrm{~kg}$, compared with a mean weight gain of approximately $0.2 \mathrm{~kg}$ in placebo-treated patients. In diabetic peripheral neuropathy pain (DPNP) placebo-controlled clinical trials, patients treated with duloxetine for up to 13 weeks experienced a mean weight loss of approximately $1.1 \mathrm{~kg}$, compared with a mean weight gain of approximately $0.2 \mathrm{~kg}$ in placebo-treated patients. In the 12-month open-label study (Study 9) (Eli Lilly and Co 2004) patients had a small weight loss early in treatment, returned to baseline weight in succeeding weeks, and had a mean weight increase of $2.1 \mathrm{~kg}$ (by repeated measures analysis) after 52 weeks of treatment.

\section{Laboratory changes}

Duloxetine treatment, for up to 13 weeks in placebo-controlled clinical trials, was associated with small mean baseline to endpoint increases in ALT, AST, CPK, and alkaline phosphatase (Eli Lilly and Co 2004). Liver transaminase elevations resulted in discontinuation of $0.4 \%$ (31/8454) of duloxetine-treated patients. In these patients, the median time to detection of transaminase elevation was about two months. Elevations of ALT to $>3$ times the upper limit of normal occurred in $0.9 \%(8 / 930)$ of duloxetine-treated and $0.3 \%$ (2/652) of placebo-treated MDD patients. In placebo-controlled studies using a fixed dose design, there was evidence of a dose-response relationship for ALT and AST elevation of $>3$ times and $>5$ times the upper limit of normal. Since duloxetine and alcohol may interact to cause liver injury, duloxetine should not be prescribed to patients with substantial alcohol use or evidence of chronic hepatic disease.

\section{Other issues}

The duloxetine package label (Anonymous 2006) notes other risks that for the most part are similar to most newer antidepressants. As with all antidepressants patients should be observed closely for clinical worsening and suicidality, especially at the beginning of a course of drug therapy, or at the time of dose changes.

Although not studied for duloxetine, patients receiving a serotonin reuptake inhibitor in combination with a monoamine oxidase inhibitor (MAOI) or even starting an MAOI shortly after discontinuing an SSRI, have reported of serious, sometimes fatal, reactions (eg, hyperthermia, rigidity, myoclonus, autonomic instability with possible rapid fluctuations of vital signs) and mental status changes, including extreme agitation leading to delirium and coma. Therefore, because duloxetine inhibits the reuptake of serotonin, duloxetine should not be used in combination with an MAOI, within at least 14 days of discontinuing treatment with an MAOI, and at least 5 days should be allowed after stopping duloxetine before starting an MAOI.

If a major depressive episode is the initial presentation of bipolar disorder, treatment with an antidepressant alone may increase the likelihood of precipitation of a mixed/manic episode. 
Since duloxetine has an increased risk of mydriasis, it should be used cautiously in patients with controlled narrow-angle glaucoma.

Since duloxetine is in a class of drugs known to affect urethral resistance, if symptoms of urinary hesitation develop during treatment with duloxetine, consideration should be given to the possibility that they might be drug related.

\section{Patient perspectives}

Depression and antidepressant treatments can impair quality of life (Wells et al 1990; Revicki et al 1998). Measuring a medication's impact on quality of life can provide evidence of the drug's broader efficacy. Patient-reported outcomes measured at baseline and end of trial included the Quality of Life in Depression Scale (QLDS) (McKenna 1992), Sheehan Disability Scale (SDS) (Sheehan et al 1996), and Patient Global Impressions - Improvement (PGI-I).

\section{Quality of life}

Four of the placebo-controlled trials (5-8) assessed quality of life with the QLDS. Duloxetine produced significantly superior improvement in mean QLDS score, compared with placebo, in both studies of duloxetine $60 \mathrm{mg}$ qd (Studies 7 and 8) (Detke et al 2000a, b) and at an $80 \mathrm{mg} / \mathrm{d}$ dose in Study 6. These findings support duloxetine's efficacy for improving quality of life among patients treated for depression.

The SDS was administered in two of the placebocontrolled studies (Studies 5 and 6). In the acute phase of both studies, patients treated with duloxetine $(80 \mathrm{mg} / \mathrm{d}$ or $120 \mathrm{mg} / \mathrm{d}$ ) or paroxetine demonstrated significantly greater improvement on SDS work item, social life item, family life item, and SDS total score compared with placebo-treated patients (Detke et al 2004; Goldstein et al 2004b).

\section{Somatic symptoms and pain}

As noted above, duloxetine has been shown to reduce physical symptoms associated with depression, particularly painful symptoms. As evidence of its independent effect in painful conditions, duloxetine has demonstrated efficacy in both diabetic peripheral neuropathy pain (Goldstein et al 2005; Raskin et al 2005) and fibromyalgia (Arnold et al 2004, 2005). Therefore, treating both the emotional and the painful physical symptoms of major depression with duloxetine is associated with improvement in patients' self-reported quality of life. Patients treated with duloxetine also demonstrated consistent improvement across trials on the PGI-I in comparison to placebo.

Finally, since duloxetine is an effective antidepressant and is also effective for DPNP, it may be that it might be particularly useful in patients with both DPNP and depression; however, this combined use has not been studied.

\section{Dosing and administration}

Taking into account the fact that once-daily dosing is advantageous, especially with regard to ease of use and compliance, duloxetine $60 \mathrm{mg}$ once daily represents the lowest dose with consistent and robust efficacy. Although $60 \mathrm{mg}$ bid demonstrated some numerical advantages over $60 \mathrm{mg}$ qd, the higher dose did not show a significant increase in efficacy but tended to have more frequent adverse events and discontinuations. As a consequence, $60 \mathrm{mg}$ is the appropriate initial dose for most patients.

\section{Conclusion}

Duloxetine demonstrated antidepressant efficacy at a dose of $60 \mathrm{mg}$ qd in two placebo-controlled, randomized, double-blind studies. Duloxetine-treated patients had significant improvement in reducing the symptoms of depression as assessed by the HAM-D ${ }_{17}$, anxious symptoms as measured by the HAM-A, and quality of life measures compared with placebo. Duloxetine also improved somatic symptoms, particularly painful symptoms which may have contributed to significantly improved remission rates compared with placebo.

Approximately $10 \%$ of the 1139 patients with MDD in placebo-controlled trials discontinued treatment due to an adverse event, compared with $4 \%$ of the 777 patients receiving placebo. In addition to nausea ( $1.4 \%$ incidence), which was the most common reason for discontinuation, dizziness, somnolence, and fatigue were the most common AEs reported as reasons for discontinuation and all were considered drug-related.

The most common AEs experienced by and more commonly reported by duloxetine than by placebo-treated patients with MDD were nausea, dry mouth, constipation, decreased appetite, fatigue, somnolence, and increased sweating. Duloxetine treatment lacks effects on ECG, increases heart rate, and has little effect on blood pressure or weight.

\section{Disclosures}

Dr. Goldstein was employed by Eli Lilly and Co, the manufacturer of duloxetine, until 2003 and owns stock in the company. His wife is employed by Eli Lilly and Co.

\section{References}

[APA] American Psychiatric Association 1994. Diagnostic and Statistical Manual of Mental Disorders, 4th ed. Washington DC: American Psychiatric Association. 
[APA] American Psychiatric Association 2000. Diagnostic and Statistical Manual of Mental Disorders, 4th ed, Text Revision. Washington DC: American Psychiatric Association.

Anonymous 2006. Cymbalta ${ }^{\circledR}$. In Medical Economics Staff (eds). Physicians Desk Reference 60th ed. Montvale, NJ: Thomson Healthcare/Medical Economics Co, p 1729-35.

Arnold L, Lu Y, Detke M, et al. 2004. A double-blind multicentral trial comparing duloxetine with placebo in the treatment of patients with fibromyalgia with and without major depressive disorder. Arthritis Rheum, 50:2974-84.

Arnold LM, Rosen A, Yili Lu Pritchett YL, et al. 2005. A randomized, double-blind, placebo-controlled trial of duloxetine in the treatment of women with fibromyalgia with or without major depressive disorder. Pain, 119:5-15.

Bailey RK, Mallinckrodt CH, Wohlreich MM, et al. 2006. Duloxetine in the treatment of major depressive disorder: comparisons of safety and efficacy. J Nat Med Assoc, 98:437-47.

Ballenger JC. 1996. Clinical evaluation of venlafaxine. J Clin Psychopharmacol, 16(Suppl 2):29S-35S.

Belsher G, Costello CG. 1988. Relapse after recovery from unipolar depression: a critical review. Psychol Bull, 104:84-96.

Bennie EH, Mullin JM, Martindale JJ. 1995. A double-blind multicenter trial comparing sertraline and fluoxetine in outpatients with major depression. J Clin Psychiatry, 56:229-37.

Berk M, du Plessis AD, Birkett M, et al. 1997. An open-label study of duloxetine hydrochloride, a mixed serotonin and noradrenaline reuptake inhibitor, in patients with DSM-III-R major depressive disorder. Lilly Duloxetine Depression Study Group. Int Clin Psychopharmacol, 12:137-40.

Bosc M, 2000. Assessment of social functioning in depression. Compr Psychiatry, 41:63-9.

Brannan SK, Mallinckrodt CH, Brown EB, et al. 2005. Duloxetine $60 \mathrm{mg}$ once-daily in the treatment of painful physical symptoms in patients with major depressive disorder. J Psychiatr Res, 39:43-53.

Bymaster FP, Lee TC, Knadler MP, et al. 2005. The dual transporter inhibitor duloxetine: a review of its preclinical pharmacology, pharmacokinetic profile, and clinical results in depression. Curr Pharm Des, 11:1475-93.

Casacalenda N, Perry JC, Looper K. 2002. Remission in major depressive disorder: a comparison of pharmacotherapy, psychotherapy, and control conditions. Am J Psychiatry, 159:1354-60.

Cohen LJ, Harris PA, Ticknor CB. 2004. Depression: new perspectives, understanding, and treatments. J Manag Care Pharm, 10(Suppl):S1-25.

Corey-Lisle PK, Nash R, Stang PE, et al. 2004. Response, partial response, and non-response in primary care treatment of depression. Arch Int Med, 164:1197-204

Croft H, Settle E, Jr, Houser T, et al. 1999. A placebo-controlled comparison of the antidepressant efficacy and effects on sexual functioning of sustained-release bupropion and sertraline. Clin Ther, 21:643-58.

Cronkite R. 1998. Life circumstances and personal resources as predictors of the ten-year course of depression. Am J Community Psychol, 26:255-80.

Danish University Antidepressant Group. 1986. Citalopram: clinical effect profile in comparison with clomipramine. A controlled multicenter study. Psychopharmacology (Berl), 90:131-8.

Danish University Antidepressant Group 1990. Paroxetine: a selective serotonin reuptake inhibitor showing better tolerance, but weaker antidepressant effect than clomipramine in a controlled multicenter study. J Affect Disord, 18:289-99.

Delgado PL, Brannan SK, Mallinckrodt CH, et al. 2005. Sexual functioning assessed in 4 double-blind placebo- and paroxetine-controlled trials of duloxetine for major depressive disorder. J Clin Psychiatry, 66:686-92.

Detke MJ, Lu Y, Goldstein DJ, Hayes JR, Demitrack MA 2002a. Duloxetine, $60 \mathrm{mg}$ once daily, for major depressive disorder: a randomized doubleblind placebo-controlled trial. J Clin Psychiatry 63:308-315.

Detke MJ, Lu Y, Goldstein DJ, et al. 2002b. Duloxetine $60 \mathrm{mg}$ once daily dosing versus placebo in the acute treatment of major depression. $J$ Psychiatr Res, 36:383-90.
Detke MJ, Wiltse CG, Mallinckrodt CH, et al. 2004. Duloxetine in the acute and long-term treatment of major depressive disorder: a placebo- and paroxetine-controlled trial. Eur Neuropsychopharmacol, 14:457-70.

Dunbar GC, Claghorn JL, Kiev A, et al. 1993. A comparison of paroxetine and placebo in depressed outpatients. Acta Psychiatr Scand, $87: 302-5$.

Dunner DL, D'Souza DN, Kajdasz DK, et al. 2005. Is treatment-associated hypomania rare with duloxetine: secondary analysis of controlled trials in non-bipolar depression. $J$ Affect Disord 87:115-9.

Dunner DL, Goldstein DJ, Mallinckrodt C, et al. 2003. Duloxetine in treatment of anxiety symptoms associated with depression. Depress Anxiety, 18:53-61.

Eli Lilly and Co. 2004. Data on File: AMCP Formatted Formulary Submission Document For Cymbalta ${ }^{\circledR}$ duloxetine $\mathrm{HCl}$ Delayed-release Capsules, September 30, 2004, Eli Lilly and Co, Inc, Indianapolis, IN, USA.

Ellingrod VL, Perry PJ. 1995. Nefazodone: a new antidepressant. Am $J$ Health Syst Pharm, 52:2799-812.

Fava M, Mallinckrodt CH, Detke MJ, et al. 2004. The effect of duloxetine on painful physical symptoms in depressed patients: do improvements in these symptoms result in higher remission rates? J Clin Psychiatr, 65:521-30.

Feighner JP, Overo K. 1999. Multicenter, placebo-controlled, fixed-dose study of citalopram in moderate-to-severe depression. J Clin Psychiatry, 60:824-30.

Gaster B, Holroyd J. 2000. St. John's wort for depression: a systematic review. Arch Intern Med, 160:152-6.

Gerber PD, Barrett JE, Barrett JA, et al. 1992. The relationship of presenting physical complaints to depressive symptoms in primary care patients $J$ Gen Int Med, 7:170-3.

Gorman JM. 1999. Mirtazapine: clinical overview. J Clin Psychiatry, 60(Suppl 17):9-13.

Goldstein DJ, Lu Y, Detke MJ, et al. 2005. Duloxetine vs. placebo in patients with painful diabetic neuropathy. Pain, 116:109-18.

Goldstein DJ, Lu Y, Detke MJ, et al. 2004a. Effects of duloxetine on painful physical symptoms associated with depression. Psychosom, 45:17-28.

Goldstein DJ, Lu Y, Detke MJ, et al. 2004b. Duloxetine in the treatment of depression: a double-blind placebo-controlled comparison with paroxetine. J Clin Psychopharmacol, 24:389-399.

Goldstein DJ, Mallinckrodt C, Lu Y, et al. 2002. Duloxetine in the treatment of major depressive disorder: a double-blind clinical trial. J Clin Psychiatry, 63:225-231.

Goldstein DJ, Potter WZ. 2004. Biological Theories of Depression and Implications for Current and New Treatments. In Ciraulo DA, Shader RI (eds) Pharmacotherapy of Depression. Totowa, NJ: Humana Press. p 1-32.

Goldstein M, Gorman JM, Marek RG, et al. 1997. The National Depressive and Manic-Depressive Association consensus statement on the undertreatment of depression. JAMA, 277: 333-340.38.

Greco T, Eckert G, Kroenke K. 2004. The outcome of physical symptoms with treatment of depression. $J$ Gen Intern Med, 19:813-8.

Greist J, McNamara RK, Mallinckrodt CH, et al 2004. Incidence and duration of antidepressant-induced nausea: duloxetine compared with paroxetine and fluoxetine. Clin Ther. In press.

Gureje O, Simon GE, Ustun TB, et al. 1997. Somatization in cross-cultural perspective: a World Health Organization study in primary care. $A m J$ Psychiatry, 154:989-95.

Gureje O, Von Korff M, Simon GE, et al. 1998. Persistent pain and wellbeing: a World Health Organization Study in Primary Care. JAMA, 280:147-51

Hays RD, Wells KB, Sherbourne CD, et al. 1995. Functioning and wellbeing outcomes of patients with depression compared with chronic general medical illnesses. Arch Gen Psychiatry, 52:11-9.

Herrman H, Patrick DL, Diehr P, et al. 2002. Longitudinal investigation of depression outcomes in primary care in six countries: the LIDO study. Functional status, health service use and treatment of people with depressive symptoms. Psychol Med, 32:889-902. 
Hirschfeld RM, Keller MB, Panico S, et al. 1997. The National Depressive and Manic-Depressive Association consensus statement on the undertreatment of depression. JAMA, 277:333-40.

Holliday SM, Plosker GL. 1993. Paroxetine. A review of its pharmacology, therapeutic use in depression and therapeutic potential in diabetic neuropathy. Drugs Aging, 3:278-99.

Jackson JL, Houston JS, Hanling SR, et al. 2001. Clinical predictors of mental disorders among medical outpatients. Arch Int Med, 161:875-9.

Johnson JA, Coons SJ, Ergo A, et al. 1998. Valuation of EuroQOL EQ-5D health states in an adult US sample. Pharmacoeconomics, 13:421-33.

Keller MB. 2003. Past, present, and future directions for defining optimal treatment outcome in depression: remission and beyond. JAMA, 289:3152-60.

Keller MB, Lavori PW, Rice J, et al. 1986. The persistent risk of chronicity in recurrent episodes of nonbipolar major depressive disorder: a prospective follow-up. Am J Psychiatry, 143:24-28.

Kessler RC, Berglund P, Demler O, et al. 2003. The epidemiology of major depressive disorder: results from the National Comorbidity Survey Replication NCS-R. JAMA, 289:3095-105.

Kessler RC, McGonagle KA, Zhao S, et al. 1994. Lifetime and 12-month prelvalence of DSM-III-R psychiatric disorders in the United States. Results from the National Comorbidity Survey. Arch Gen Psychiatry, 51:8-19.

Kessler RC, Nelson CB, McGonagle KA, et al. 1996. Comorbidity of DSMIII-R major depressive disorder in the general population: results from the US National Comorbidity Survey. Br J Psychiatry, (Suppl 30):17-30.

Kessler RC, Zhao S, Blazer DG, et al. 1997. Prevalence, correlates and course of minor depression and major depression in the national Comorbidity survey. J Affect Disord, 45:19-30.

Klerman G, Weissman M. 1992. The course, morbidity, and costs of depression. Arch Gen Psychiatry, 49:831-4.

Kornstein SG, Wohlreich MM, Mallinckrodt CH, Watkin JG, Stewart DE 2006. Duloxetine efficacy for major depressive disorder in male vs. female patients: data from 7 randomized, double-blind, placebo-controlled trials. J Clin Psychiatry, 67:761-70.

Kroenke K, Price RK. 1993. Symptoms in the community: prevalence, classification, and psychiatric comorbidity. Arch Intern Med, $153: 2474-80$

Kroenke K, West SL, Swindle R, et al. 2001. Similar effectiveness of paroxetine, fluoxetine, and sertraline in primary care: a randomized trial. JAMA, 286:2947-55.

Kupfer DJ, Frank E, Perel JM, et al. 1992. Five-year outcome for maintenance therapies in recurrent depression. Arch Gen Psychiatry, 49:769-73.

Lantz RJ, Gillespie TA, Rash TJ, et al. 2003. Metabolism, excretion, and pharmacokinetics of duloxetine in healthy human subjects. Drug Metab Disp, 31:1142-50.

Mallinckrodt CH, Raskin J, Wohlreich MM, et al. 2004. The efficacy of duloxetine: a comprehensive summary of results from MMRM and LOCF_ANCOVA in eight clinical trials. BMC Psychiatry, 4:26.

Mallinckrodt CH, Watkin JG, Liu C, et al. 2005. Duloxetine in the treatment of Major Depressive Disorder: a comparison of efficacy in patients with and without melancholic features. BMC Psychiatry, 5:1.

Mason J, Freemantle N, Eccles M. 2000. Fatal toxicity associated with antidepressant use in primary care. Br J Gen Pract. 50:366-70.

McGahuey CA, Gelenberg AJ, Laukes CA, et al 2000) The Arizona Sexual Experience Scale ASEX): reliability and validity. $J$ Sex Marital Ther, 26:25-40.

McKenna SP, Hunt SM. 1992. A new measure of quality of life in depression: testing reliability and construct validity of the QLDS. Health Policy, 22:321-30.

Mulrow CD, Williams JW Jr, Chiquette E, et al. 2000. Efficacy of newer medications for treating depression in primary care patients. Am $J$ Med, 108:54-64.

Nelson JC. 1998. Synergistic effects of 5-HT and NE. Depress Anxiety, 7(Suppl 1):5-6.
Nelson JC, Mazure CM, Bowers MB Jr, et al. 1991. A preliminary, open study of the combination of fluoxetine and desipramine for rapid treatment of major depression. Arch Gen Psychiatry, 48:303-7.

Nelson JC, Wohlreich MM, Mallinckrodt CH, et al. 2005. Duloxetine for the treatment of major depressive disorder in older patients. Am J Geriatr Psychiatry, 13:227-35.

Patris M, Bouchard JM, Bougerol T, et al. 1996. Citalopram versus fluoxetine: a double-blind, controlled, multicentre, phase III trial in patients with unipolar major depression treated in general practice. Int Clin Psychopharmacol, 11:129-36.

Penninx BW, Rejeski WJ, Pandya J, et al. 2002. Exercise and depressive symptoms: a comparison of aerobic and resistance exercise effects on emotional and physical function in older persons with high and low depressive symptomatology. J Gerontol B Psychol Sci Soc Sci, 57:124-32.

Perahia DG, Gilaberte I, Wang F, et al. 2006. Duloxetine in the prevention of relapse of major depressive disorder: double-blind placebo-controlled study. Br J Psychiatry, 188:346-53.

Perahia DG, Kajdasz DK, Walker DJ, et al. 2006. Duloxetine $60 \mathrm{mg}$ once daily in the treatment of milder major depressive disorder. Int J Clin Pract, 60:613-20.

Peretti S, Judge R, Hindmarch I. 2000. Safety and tolerability considerations: tricyclic antidepressants vs. selective serotonin reuptake inhibitors. Acta Psychiatr Scand Suppl, 403:17-25.

Posse M, Hallstrom T. 1998. Depressive disorders among somatizing patients in primary health care. Acta Psychiatr Scand, 98:187-92.

Raskin J, Goldstein DJ, Mallinckrodt CH, et al. 2003. Duloxetine in the long-term treatment of major depressive disorder. J Clin Psychiatr, 64:1237-44.

Raskin J, Pritchett YL, Wang F, et al. 2005. A double-blind, randomized multicenter trial comparing duloxetine with placebo in the management of diabetic peripheral neuropathic pain. Pain Med, 6:346-56.

Revicki DA, Simon GE, Chan K. 1998. Depression, health-related quality of life, and medical cost outcomes of receiving recommended levels of antidepressant treatment. J Fam Pract, 47:446-52.

Schulberg HC, Katon WJ, Simon GE, et al. 1999. Best clinical practice: guidelines for managing major depression in primary medical care. $J$ Clin Psychiatry, 60(Suppl 7):19-26.

Sechter D, Troy S, Paternetti S, et al. 1999. A double-blind comparison of sertraline and fluoxetine in the treatment of major depressive episode in outpatients. Eur Psychiatry, 14:41-8.

Sheehan D, Harnett-Sheehan K, Raj B. 1996. The measurement of disability. Int Clin Psychopharmacol, 13:89-95.

Simon GE, Von Korff M. 1991. Somatization and psychiatric disorder in the NIMH Epidemiologic Catchment Area study. Am J Psychiatry, 148:1494-500.

Simon GE, Von Korff M, Piccinelli M, et al. 1999. An international study of the relation between somatic symptoms and depression. $N$ Engl $J$ Med, 341:1329-35.

Simon GE, Chisholm D, Treglia M, et al. 2002. Course of depression, health services costs, and work productivity in an international primary care study. Gen Hosp Psychiatry, 24:328-35.

Skinner MH, Kuan HY, Pan A, et al. 2003. Duloxetine is both an inhibitor and a substrate of cytochrome P4502D6 in healthy volunteers. Clin Pharm Ther, 73:170-7.

Skinner MH, Kuan HY, Skerjanec A, et al. 2004. Effect of age on the pharmacokinetics of duloxetine in women. Br J Clin Pharm, 57:54-61.

Stahl SM. 2000. Placebo-controlled comparison of the selective serotonin reuptake inhibitors citalopram and sertraline. Biol Psychiatry, 48:894-901.

Suri A, Reddy S, Gonzales C, et al. 2005. Duloxetine pharmacokinetics in cirrhotics compared with healthy subjects. Int J Clin Pharm Ther, 43:78-84.

Sutor B, Rummans TA, Jowsey SG, et al. 1998. Major depression in medically ill patients. Mayo Clin Proc, 73:329-37. 
Swindle RW, Cronkite RC, Moos RH. 1998. Risk factors for sustained nonremission of depressive symptoms: A four-year follow-up. J Nerv Ment Dis, 186:462-9.

Thase ME. 2002. Studying new antidepressants: if there were a light at the end of the tunnel, could we see it? J Clin Psychiatry, 63(Suppl 2):24-8.

Thase ME, Tran PV, Wiltse C, et al. 2005. Cardiovascular profile of duloxetine, a dual reuptake inhibitor of serotonin and norepinephrine. $J$ Clin Psychopharmacol, 25:132-40.

Tran PV, Bymaster FP, McNamara RK, et al. 2003. Dual monoamine modulation for improved treatment of major depressive disorder. $J$ Clin Psychopharmacol, 23:78-86.

Von Korff M, Simon G. 1996. The relationship between pain and depression. Br J Psychiatry Suppl, 30:101-8.

Ware JE, Snow KK, Kosinski M, et al. 1995. Comparison of methods for scoring and statistical analysis of SF-36 health profile and summary measures: summary of results from the Medical Outcomes Study. Med Care, 33(Suppl 4):AS264-79.

Weiner RD, Coffey CE. 1993. Electroconvulsive therapy in the medical and neurological patient. In Stoudemire A, Fogel BS (eds). Psychiatric Care of the Medical Patient. New York, NY: Oxford University Press.
Wells KB, Stewart A, Hays RD, et al. 1989. The functioning and well-being of depressed patients. Results from the Medical Outcomes Study. JAMA, 262:914-9.

Williams JW Jr, Mulrow CD, Chiquette E, et al. 2000. A systematic review of newer pharmacotherapies for depression in adults: evidence report summary. Ann Intern Med, 132:743-56.

Wohlreich MM, Martinez JM, Mallinckrodt CH, et al. 2005. An open-label study of duloxetine for the treatment of major depressive disorder: comparison of switching versus initiating treatment approaches. J Clin Psychopharmacol, 25:552-60. 
